\title{
Viabilidade econômica da implantação de um banco de capacitores em unidade armazenadora de grãos
}

Economic feasibility of the installation of capacitor banks in a grain storage

Gustavo Veloso'; Meyriele Pires de Camargo ${ }^{2 *}$

${ }^{1}$ Companhia Nacional de Abastecimento - Engenheiro Agrícola - SGAN 914, conjunto H, bloco B, Asa Norte, CEP 70790-148, Brasília (DF), Brasil

${ }^{2}$ Escola Superior de Agricultura "Luiz de Queiroz", Universidade de São Paulo - Engenheira Agrônoma, Mestre em Fitopatologia - Departamento de Fitopatologia e

Nematologia, Av. Pádua Dias, 11, CEP 13418-200, Piracicaba (SP), Brasil <meyrielecamargo@usp.br>

\section{Resumo}

As unidades de armazenagem de grãos apresentam elevado consumo de energia elétrica e o aumento do seu preço tem aumentado o custo operacional delas. Esses gastos podem ser diminuídos pela correção do fator de potência através da instalação de bancos de capacitores. Este trabalho analisou a viabilidade econômica da implantação desse tipo de equipamento em uma unidade armazenadora de grãos sediada no município de Brasília, Distrito Federal. O custo da implantação do banco de capacitores foi comparado com a economia advinda da redução dos valores mensais com o consumo reativo de energia. Os cálculos consideram financiamento bancário do valor total a uma taxa de juros de $8,5 \%$ ao ano. A taxa mínima de atratividade é 4,46\% ao semestre [a.s.]. Os indicadores econômicos utilizados foram: Valor Presente Líquido [VPL], Taxa Interna de Retorno [TIR] e Payback. O investimento considerado foi de R\$26.772,03. O projeto tem VPL de R \$ 7.228,63, TIR de 9,34\% a.s. e Payback de três anos e quatro meses. Com base nesses resultados o investimento é atrativo e economicamente viável.

Palavras-chave: capacitores, energia reativa, indicadores econômicos

\begin{abstract}
Grain storage complexes require a high consumption of electric energy and the increase in the price of electricity has generated a large impact on their operating costs. One alternative is the correction of the power factor through the installation of capacitor banks. This work aimed to evaluate the economic feasibility of a capacitor installation in a grain storage located in Brasília, Distrito Federal. The cost of deploying the capacitor bank was compared to the values saved in the monthly payments with the reactive energy consumption. To purchase the capacitor bank, financing was simulated with an interest rate of $8.5 \%$ per year. The minimum attractive rate of return [MARR] was fixed on $4.46 \%$ per semester [p.s.]. Economic indicators estimated were Net Present Value [NPV], Internal Rate of Return [IRR] and simple Payback. The total project cost was R $\$ 26,772.03$. The investment presented a NPV of R $\$ 7,228.63$. IRR was $9.34 \%$ p.s., higher than the MARR (4.46\% p.s.). Payback period was three years and four months. Based on the results obtained from NPV, IRR and Payback, the investment proved to be economically viable and attractive.
\end{abstract}

Keywords: capacitors, reactive energy, economic indicators

\section{Introdução}

As unidades armazenadoras consomem grande quantidade de energia elétrica, principalmente na utilização de motores elétricos. Para o funcionamento desses equipamentos, a energia reativa é fundamental. Entretanto, é desejável que a utilização da energia reativa seja a menor possível, já que o excedente requer condutores de maior secção e transformadores de maior capacidade, acarretando perdas técnicas por quedas de tensão e aquecimento (Fragoas, 2008) ${ }^{1}$.
O fator de potência é um índice do uso de energia e seu correto controle é de suma importância para as unidades consumidoras. Pelo fato de ser mensurado pelos sistemas de medição das concessionárias de energia elétrica, em algumas situações, o fator de potência pode acarretar custos adicionais significativos na fatura de energia elétrica (Silva, 2009)2 ${ }^{2}$. Conforme art. 76 da Resolução Normativa $n^{\circ} 414$, para fins de cobrança, o fator de potência deverá ser verificado pela distribuidora por meio de medição permanente, sendo obrigatória para unidades consumidoras do grupo A (ANEEL, 2012). Os

${ }^{1}$ Fragoas, A.G. 2008. Estudo de caso do uso de bancos de capacitores em uma rede de distribuição primária - indicativos da sua viabilidade econômica. Trabalho de conclusão de Curso de Engenharia Elétrica. Universidade de São Paulo, São Carlos, São Paulo, Brasil. Disponível em: < http://www.tcc.sc. usp.br/tce/disponiveis/18/180500/tce26032010-145421/?\&lang=br>. Acesso em: 05 mar. 2016.

2 Silva, M.C.I. 2009. Correção do fator de potência de cargas industriais com dinâmica rápida. Dissertação de Mestrado em Engenharia Elétrica. Universidade Federal de Minas Gerais, Belo Horizonte, Minas Gerais, Brasil. Disponível em: <http://www.ppgee.ufmg.br/defesas/129M.PDF>. Acesso em: 04 ago. 2016. 
consumidores atendidos em alta tensão (acima de 2,3kV) como indústrias, shopping centers e alguns edifícios comerciais, são classificados no Grupo A. Esse grupo é subdividido em subgrupos de acordo com a tensão de atendimento, na qual pode-se enquadrar a unidade armazenadora, conforme o art. 2, inciso XXXVII, e da Resolução Normativa $n^{\circ} 414$, que define a faixa de tensão de fornecimento de $2,3 \mathrm{kV}$ a $25 \mathrm{kV}$ (ANEEL, 2012).

Os art. 96 e 97, de 9 de setembro de 2010, da Resolução Normativa no 414 (ANEEL, 2012) autorizam a cobrança dos montantes de energia elétrica e demanda de potência reativa que excederem o limite permitido, com a aplicação das cobranças estabelecidas nos artigos citados, a serem adicionadas ao faturamento regular de unidades consumidoras do grupo A. No art. 95, a presente resolução determina o limite mínimo de fator de potência de referência " $f_{R}$ ", indutivo ou capacitivo, sendo o valor de 0,92 o mínimo permitido para as unidades consumidoras do grupo A. Conforme a legislação, a cobrança devido ao baixo fator de potência é proveniente do excedente reativo consumido pelas unidades enquadradas na tarifa horo-sazonal e convencional.

Visando corrigir o fator de potência dos motores elétricos, os capacitores são instalados como uma fonte de energia reativa, reduzindo perdas na geração, transmissão e prolongando a vida útil dos equipamentos elétricos (Flarys, 2006). A eficiência do consumo de energia é indicada pelo fator de potência, sendo que valores elevados de fator de potência estão relacionados a alta eficiência, ou seja, quase toda energia fornecida pela fonte é consumida pela carga. Da mesma forma, um baixo valor de potência indica baixa eficiência energética dos circuitos elétricos, pois o fluxo de energia será inteiramente reativo, e a energia armazenada é devolvida totalmente a fonte em cada ciclo (CODI, 2004). Portanto, pode-se dizer que para reduzidos valores de fator de potência será necessária uma maior quantidade de potência aparente para se obter a mesma potência ativa.

A utilização de bancos de capacitores próximos da carga é o método para se evitar custos adicionais com excedente de energia reativa e baixa eficiência energética dos circuitos elétricos. Dessa forma, a energia reativa é disponibilizada pelos capacitores, ao invés de ser obtida do sistema elétrico (CODI, 1993). Capaz de acumular energia elétrica e corrigir o fator de potência, o capacitor é basicamente composto por duas placas condutoras e isoladas, fornecendo corrente elétrica para compensar a defasagem gerada pelas cargas indutivas quando conectado a uma fonte de tensão nas suas pontas (Mamede Filho, 2007).
De acordo com Amorim $(2008)^{3}$ um grande número de empreendimentos industriais e comerciais não realiza a correção do fator de potência em suas plantas. Isso ocorre devido à falta de engenharia no corpo funcional e, especialmente, pelo fato da multa resultante por baixo fator de potência ser expressa nas faturas de energia elétrica com diversas terminologias, como unidade de faturamento de demanda reativa [UFDR], unidade de faturamento de energia reativa [UFER], consumo reativo excedente na ponta/fora de ponta [CRE], energia excedente $[\mathrm{EC}]$, energia reativa excedente [EREX], entre outras, situações que descaracterizam o ônus por ineficiência do consumo de energia.

Para Duailibe (2000) a correção do fator de potência através da instalação do banco de capacitor é a forma mais viável financeiramente. De acordo com Silva (2009) 4 o uso de bancos de capacitores automáticos em instalações elétricas de baixa tensão seria uma boa solução para corrigir o fator de potência. Amorim $(2008)^{5}$ relatou que valores maiores que 0,95 de fator de potência na baixa tensão resultaram em um aumento da capacidade de distribuição/transmissão de energia elétrica de $3,25 \%$, aumento este que se equipara ao ganho obtido com o horário de verão.

Diante do exposto, o trabalho teve como objetivo explorar a correção do fator de potência em uma unidade armazenadora de grãos em Brasília, Distrito Federal, verificando os benefícios econômicos do uso de banco de capacitores e a atratividade financeira da implantação de um banco de capacitores em um armazém de grãos.

\section{Material e Métodos}

\section{Caracterização da unidade consumidora}

A unidade armazenadora alvo do estudo foi construída em 1984, em Brasília, DF. A unidade opera apenas em horário comercial, entre 8 h00 e 17 h00 e prestou serviços de armazéns gerais.

De acordo com a classificação Nacional de Atividades Econômicas [CNAE] do Instituto Brasileiro de Geografia e Estatística [IBGE], e conforme exigência da ANEEL (2012) que determina a caracterização de atividade industrial, a unidade armazenadora enquadrouse no código H 5211-7/01. O armazém foi classificado por espécie a granel tipo silo e possuiu capacidade estática de armazenamento de 25.800 toneladas. A ocupação média do armazém no período analisado foi de $45 \%$ da sua capacidade estática indicando significativa capacidade ociosa. Mas, o aumento do nível de ocupação resultará no aumento do consumo de energia elétrica.

A unidade consumidora possuiu uma demanda contratada de $105 \mathrm{~kW}$ de potência. Ela foi classificada como consumidor do grupo A, com tensão igual ou

3 Amorim, E. 2008. Efeitos da correção do FP na BT sob o ponto de vista da eficiência energética. In: ABINEE TEC. São Paulo, São Paulo, Brasil. Disponível em<http://www.tec.abinee.org.br/2008/arquivos/20a2_1.pdf>. Acesso em: 03 ago. 2016.

${ }^{4}$ Silva, M.C.I. 2009. Correção do fator de potência de cargas industriais com dinâmica rápida. Dissertação de Mestrado em Engenharia Elétrica. Universidade Federal de Minas Gerais, Belo Horizonte, Minas Gerais, Brasil. Disponível em: <http://www.ppgee.ufmg.br/defesas/129M.PDF>. Acesso em: 04 ago. 2016.

${ }^{5}$ Idem nota 3 
superior a $2,3 \mathrm{kV}$, subgrupo A4, com tensão entre $2,3 \mathrm{kV}$ e $25 \mathrm{kV}$. Na modalidade tarifária, enquadra-se na categoria horo-sazonal verde.

\section{Mensuração do consumo de energia reativa}

A unidade consumidora enquadrou-se no grupo A tarifa verde, e arcou com custos pelo consumo de energia reativa na ponta e fora de ponta, e a demanda reativa.

$\mathrm{O}$ artigo $\mathrm{n}^{\circ} 96$ da Resolução Normativa $\mathrm{n}^{\circ} 414$ (ANEEL, 2012), dispõe que, para as unidades consumidoras que possuam sistemas de medição apropriados, os valores correspondentes à energia elétrica e demanda de potência reativa excedente são apuradas pela concessionária conforme as eq. (1) e (2).

$$
E_{R E}=\sum_{T=1}^{n 1}\left[E_{E A M} \times\left(\frac{f_{R}}{f_{T}}-1\right)\right] \times V_{E R E}
$$

onde $\mathrm{E}_{\mathrm{RE}}$ : valor correspondente à energia elétrica reativa excedente à quantidade permitida pelo fator de potência de referência " $f_{R}$ ", no período de faturamento, em $\mathrm{R} \$$; EEAM $_{\mathrm{T}}$ : montante de energia elétrica ativa medida em cada intervalo "T" de uma hora, durante o período de faturamento, em MWh; $f_{R}$ : fator de potência de referência igual a 0,$92 ; \mathrm{f}_{\mathrm{T}}$ : fator de potência da unidade consumidora, calculando em cada intervalo " $\mathrm{T}$ " de uma hora, durante o período de faturamento; e, $\mathrm{VR}_{\mathrm{ERE}}$ : é o valor de referência equivalente à tarifa de energia "TE" aplicável ao subgrupo B1, em R \$ MWh-1;

$$
\mathrm{D}_{\mathrm{RE}}(\mathrm{p})=\left[\mathrm{MAX}_{\mathrm{T}=1}^{\mathrm{n} 2}\left(\mathrm{PAM}_{\mathrm{T}} \times \frac{\mathrm{f}_{\mathrm{R}}}{\mathrm{f}_{\mathrm{T}}}\right)-\mathrm{PAF}_{(\mathrm{p})}\right] \times \mathrm{VR}_{\mathrm{DRE}}
$$

onde $\mathrm{D}_{\mathrm{RE}}(\mathrm{p})$ : valor correspondente à demanda de potência reativa excedente à quantidade permitida pelo fator de potência de referência, no período de faturamento, em R\$; $\mathrm{PAM}_{\mathrm{T}}$ : demanda de potência ativa medida durante o período de faturamento, em $\mathrm{kW}$; $\operatorname{PAF}(\mathrm{p})$ : demanda de potência ativa faturável no período de faturamento, em $\mathrm{kW}$; VR $\mathrm{VRE}_{\mathrm{DE}}$ : valor de referência, em $\mathrm{R} \$ \mathrm{~kW}^{-1}$, equivalente às tarifas de demanda de potência para o posto horário fora de ponta das tarifas de fornecimento aplicáveis aos subgrupos do grupo; MAX: função que identifica o valor máximo da equação, dentro dos parênteses correspondentes, em cada posto tarifário "p"; T: intervalo de uma hora, no período de faturamento; p: posto tarifário ponta ou fora de ponta para as modalidades tarifárias horárias ou período de faturamento para a modalidade tarifária convencional binômia; n1: número de intervalos de integralização "T" do período de faturamento para os postos tarifários ponta e fora de ponta; e, n2: número de intervalos de integralização "T", por posto tarifário “p”, no período de faturamento.

De acordo com o $₫ 1^{\circ}$ da Resolução, para a apuração do $E_{R E}$ e $D_{R E}(p)$, deve-se considerar: $i$. o período de 6 (seis) horas consecutivas, compreendido, a critério da distribuidora, entre $23 \mathrm{~h} 30 \mathrm{~min}$ e $6 \mathrm{~h} 30 \mathrm{~min}$, somente os fatores de potência " $\mathrm{f}_{\mathrm{T}}$ " inferiores a 0,92 capacitivo, identificados em cada intervalo de uma hora "T"; ii. o período diário complementar ao definido no inciso I, somente os fatores de potência " $\mathrm{f}_{\mathrm{T}}$ " inferiores a 0,92 indutivo, identificados em cada intervalo de uma hora "T" (ANEEL, 2012).

A concessionária que forneceu energia elétrica para unidade avaliada expressou na fatura o consumo excedente de energia reativa como Energia Reativa Excedente [EREX], cuja unidade de medida é UFER, e a Demanda Reativa Excedente [DREX], expressa na fatura pela unidade de medida UFDR. Para verificar e mensurar o consumo mensal, a concessionária utilizou o medidor eletrônico classe de exatidão $\mathrm{B}$, marca ELO, modelo ELO 2131T, aprovado pelo INMETRO através da Portaria Inmetro/Dimel no 0219, de 15 de outubro de 2013, o qual realiza a medição de energia elétrica ativa e reativa, monofásica e bidirecional.

\section{Obtenção dos dados}

Os dados de consumo foram extraídos das faturas de energia elétrica da unidade armazenadora entre janeiro de 2014 e agosto de 2016, e de informações fornecidas pela concessionária de energia elétrica. As faturas registraram os valores pagos pelo excedente reativo EREX ponta e fora de ponta e a demanda de potência reativa DREX (Tabela 1). Nesses valores foram adicionados $21 \%$ de Imposto sobre a Circulação de Mercadorias e Serviços [ICMS]. A figura 1 demonstra a variação dos valores das faturas de energia elétrica com e sem o consumo reativo no período analisado.

Conforme exposto na Instrução Normativa da Receita Federal Brasileira N²34 de 11 de janeiro de 2012, a unidade armazenadora realizou a retenção de tributos federais sobre os pagamentos efetuados a pessoas jurídicas, pelo fornecimento de bens ou prestação de serviços em geral, sendo $3 \%$ da Contribuição para o financiamento da Seguridade Social [COFINS], $1,2 \%$ de Imposto de Renda, $1 \%$ de Contribuição Social sobre o Lucro Líquido [CSSL] e 0,65\% da Contribuição para o PIS/PASEP. Os tributos supracitados presentes nas faturas de energia elétrica são retidos. Dessa forma, não foram considerados sobre os valores da tabela 1 . 
Tabela 1. Valores desembolsados para o pagamento do consumo reativo de energia em uma unidade de armazenamento de grãos em Brasília, Distrito Federal

\begin{tabular}{|c|c|c|c|c|c|c|c|c|c|}
\hline Mês/Ano & $\begin{array}{l}\text { EREX } \\
\text { ponta }^{1}\end{array}$ & UFER $^{2}$ & $\begin{array}{c}\text { EREX } \\
\text { f.ponta }\end{array}$ & UFER & $\mathrm{DREX}^{4}$ & UFDR $^{5}$ & Total & $\begin{array}{c}\text { Fatura sem } \\
\text { consumo } \\
\text { reativo }\end{array}$ & $\begin{array}{c}\text { Fatura com } \\
\text { consumo } \\
\text { reativo }\end{array}$ \\
\hline & --- R\$ --- & & --- R\$ --- & & -- R\$ -- & & -------- & $\mathrm{R} \$$ & ------------- \\
\hline jan/14 & 0 & 0 & 1451,76 & 7460 & 0 & 0 & 1451,76 & 2212,87 & 3664,63 \\
\hline $\mathrm{fev} / 14$ & 0 & 0 & 1403,7 & 7390 & 0 & 0 & 1403,70 & 2107,73 & 3511,43 \\
\hline $\mathrm{mar} / 14$ & 0 & 0 & 1320,3 & 6751 & 0 & 0 & 1320,30 & 2906,86 & 4227,16 \\
\hline $\mathrm{abr} / 14$ & 0 & 0 & 1482,52 & 7532 & 0 & 0 & 1482,52 & 2365,94 & 3848,46 \\
\hline maio/14 & 0 & 0 & 1300,54 & 7162 & 0 & 0 & 1300,54 & 2325,94 & 3626,48 \\
\hline jun/14 & 0 & 0 & 1328,55 & 7449 & 0 & 0 & 1328,55 & 1999,38 & 3327,93 \\
\hline jul/14 & 0 & 0 & 1317,72 & 7228 & 0 & 0 & 1317,72 & 2877,01 & 4194,73 \\
\hline ago/14 & 0 & 0 & 1340,56 & 7396 & 0 & 0 & 1340,56 & 2072,71 & 3413,27 \\
\hline set/14 & 0 & 0 & 1690,56 & 7103 & 0 & 0 & 1690,56 & 2617,67 & 4308,23 \\
\hline out/14 & 0,45 & 2 & 1049,05 & 4578 & 0 & 0 & 1049,50 & 3975,29 & 5024,79 \\
\hline nov/14 & 0 & 0 & 900,06 & 3919 & 0 & 0 & 900,06 & 3511,46 & 4411,52 \\
\hline $\mathrm{dez} / 14$ & 0 & 0 & 870,33 & 3783 & 0 & 0 & 870,33 & 3501,37 & 4371,7 \\
\hline $\mathrm{jan} / 15$ & 1,79 & 8 & 765,66 & 3393 & 0 & 0 & 767,45 & 3016,43 & 3783,88 \\
\hline $\mathrm{fev} / 15$ & 0 & 0 & 749,59 & 3302 & 0 & 0 & 749,59 & 3582,36 & 4331,95 \\
\hline $\mathrm{mar} / 15$ & 0 & 0 & 755,48 & 3279 & 0 & 0 & 755,48 & 3348,3 & 4103,78 \\
\hline $\mathrm{abr} / 15$ & 0 & 0 & 613,17 & 2491 & 0 & 0 & 613,17 & 5535,07 & 6148,24 \\
\hline maio/15 & 0,99 & 4 & 820,3 & 3315 & 58,48 & 10 & 879,77 & 4211,81 & 5091,58 \\
\hline jun/15 & 0 & 0 & 490,37 & 1947 & 0 & 0 & 490,37 & 11245,41 & 11735,78 \\
\hline $\mathrm{jul} / 15$ & 0 & 0 & 798,08 & 3097 & 0 & 0 & 798,08 & 7661,54 & 8459,62 \\
\hline ago/15 & 0 & 0 & 792,76 & 3170 & 0 & 0 & 792,76 & 3293,75 & 4086,51 \\
\hline set/15 & 0 & 0 & 809,82 & 3049 & 0 & 0 & 809,82 & 3405,74 & 4215,56 \\
\hline out/15 & 0 & 16 & 1279,76 & 4105 & 0 & 0 & 1279,76 & 5222,71 & 6502,47 \\
\hline nov/15 & 3,7 & 12 & 1206,72 & 3913 & 0 & 0 & 1210,42 & 6455,82 & 7666,24 \\
\hline $\mathrm{dez} / 15$ & 0 & 0 & 1263,92 & 4052 & 0 & 0 & 1263,92 & 6174,91 & 7438,83 \\
\hline $\mathrm{jan} / 16$ & 0 & 0 & 1247,81 & 3975 & 0 & 0 & 1247,81 & 5581,28 & 6829,09 \\
\hline $\mathrm{fev} / 16$ & 0 & 0 & 1268,92 & 4023 & 0 & 0 & 1268,92 & 5838,3 & 7107,22 \\
\hline $\mathrm{mar} / 16$ & 0,31 & 1 & 1157,99 & 3713 & 0 & 0 & 1158,3 & 4720,18 & 5878,48 \\
\hline $\mathrm{abr} / 16$ & 0 & 0 & 1073,79 & 3429 & 0 & 0 & 1073,79 & 5342,04 & 6415,83 \\
\hline maio/16 & 0,31 & 1 & 1041,15 & 3259 & 0 & 0 & 1041,46 & 4752,77 & 5794,23 \\
\hline jun/16 & 0 & 0 & 990,76 & 3184 & 0 & 0 & 990,76 & 5815,24 & 6806,00 \\
\hline jul/16 & 0 & 0 & 998,2 & 3220 & 0 & 0 & 998,2 & 4731,54 & 5729,74 \\
\hline ago/16 & 0 & 0 & 882,39 & 2964 & 0 & 0 & 882,39 & 3730,74 & 4613,13 \\
\hline Total & 7,55 & 44 & 34462,29 & 144631,0 & 58,48 & 10 & 34528,32 & 136140,17 & 170668,49 \\
\hline
\end{tabular}

${ }^{1}$ Energia reativa excedente na ponta (EREX ponta), ${ }^{2}$ Unidade de faturamento de energia reativa [UFER], ${ }^{3}$ Energia reativa excedente fora de ponta (EREX f.ponta), ${ }^{4}$ Demanda Reativa Excedente [DREX], ${ }^{5}$ Unidade de faturamento de demanda reativa [UFDR] Fonte: Companhia Energética de Brasília [CEB] (2016)

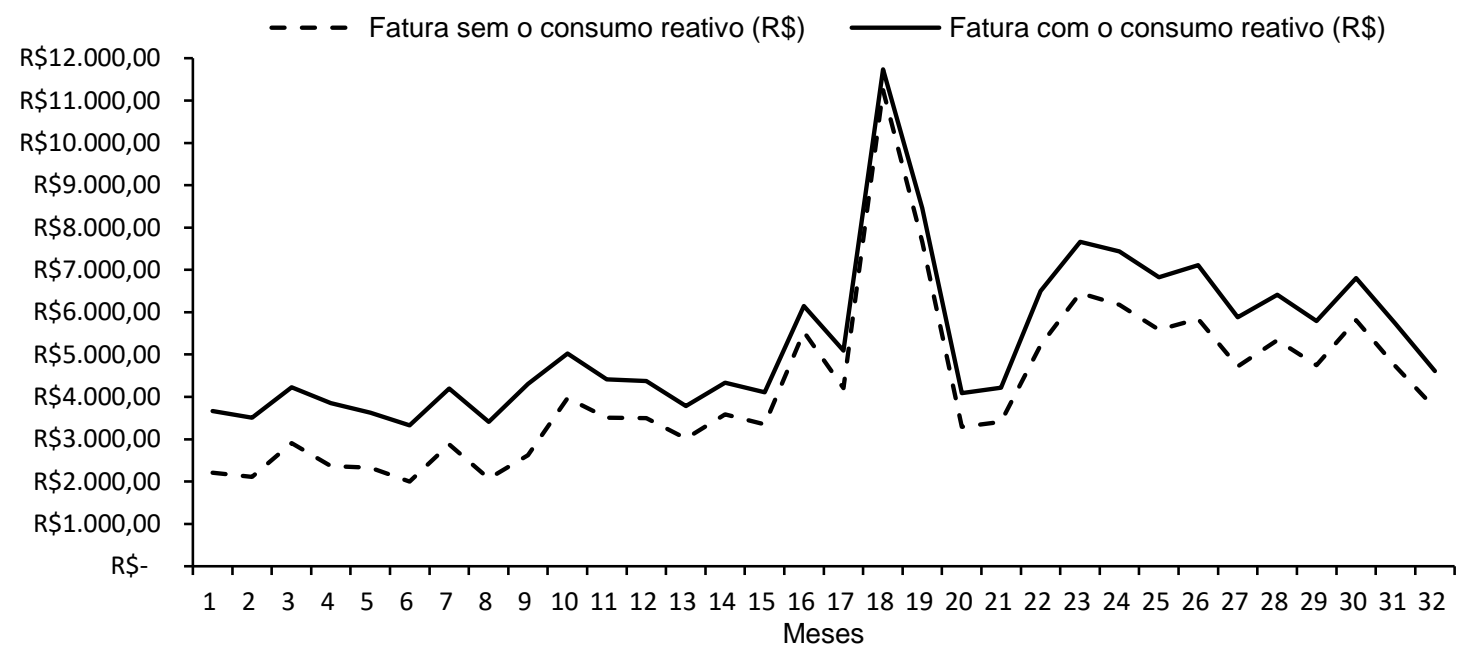

Figura 1. Variação dos custos $(\mathrm{R} \$)$ das faturas de energia elétrica com e sem o consumo reativo de energia Fonte: Adaptado de Companhia Energética de Brasília [CEB] (2014, 2015 e 2016) 


\section{Dimensionamento e orçamento do banco de capacitor}

A unidade armazenadora possuiu potência aparente total prevista no projeto inicial de 1,0 MVA, sendo dois transformadores de $500 \mathrm{kVA}$ instalados na subestação. Destes, apenas um estava em funcionamento. Portanto, a potência aparente (S) disponível foi de $500 \mathrm{kVA}$.

Quando construída, a unidade armazenadora apresentava fator de potência de referência no valor de 0,85 . Atualmente, de acordo com a Resolução Normativa $\mathrm{n}^{\circ} 414$ (ANEEL, 2012), o fator de potência de referência é estipulado em 0,92 . Assim, levando-se em consideração esse critério e, conforme recomendação técnica, o valor adotado para correção foi de 0,95 .

A distribuidora de energia elétrica informou que no período avaliado o menor fator de potência foi de 0,76. Esse valor foi corrigido para $0,95 \mathrm{com}$ a instalação do banco de capacitores no barramento geral de baixa tensão. A potência reativa do capacitor foi calculada pela eq. (3) proposta por Mamede Filho (2007).

$$
\mathrm{Q}=\mathrm{P} \times\left[\tan \left(\operatorname{arcos}\left(\mathrm{FP}_{1}\right)\right)-\tan \left(\operatorname{arcos}\left(\mathrm{FP}_{2}\right)\right)\right]
$$

onde Q: potência reativa do capacitor, em kVAR; P: potência ativa total, em $\mathrm{kW} ; \mathrm{FP}_{1}$ : menor fator de potência, adimensional; $\mathrm{FP}_{2}$ : fator de potência desejado, adimensional.

Conforme mencionado, a potência aparente $[\mathrm{S}]$ disponível foi de $500 \mathrm{kVA}$ e o fator de potência desejado de 0,95 . Sendo assim, calculou-se a potência ativa total por meio da eq. (4). Assim, obteve-se uma potência ativa total de $475 \mathrm{~kW}$.

$$
\mathrm{P}=\mathrm{S} \times \mathrm{FP}_{2}
$$

onde P: potência ativa total, em kW; S: potência aparente, em kVA; $\mathrm{FP}_{2}$ : fator de potência desejado, adimensional.

Com esses valores, obteve-se a potência reativa do banco de acordo com a eq. (3), resultando em $250 \mathrm{kVAR}$.

Para aumentar a eficiência e corrigir o fator de potência, foi necessária a montagem de um banco de capacitores no barramento geral de baixa tensão. Para tanto, foram cotados três orçamentos com empresas especializadas na montagem e instalação de um banco capacitor automático de $250 \mathrm{kVAR}$ com $380 \mathrm{~V}$ de tensão. Optou-se pelo orçamento que melhor atendeu às necessidades da unidade em relação a valores, e cumprindo as exigências normativas da Associação Brasileira de Normas Técnicas [ABNT], legislação municipal, estadual e federal. No orçamento também foram inclusos os valores referentes a instalação, "startup" do painel e fornecimento de todo material necessário para o perfeito funcionamento (Tabela 2).
Tabela 2. Orçamento do banco de capacitores para uma unidade de armazenamento de grãos

\begin{tabular}{lc}
\hline Descrição & Valor \\
\hline & $-----\mathrm{R} \$-----$ \\
Total material & $19.998,87$ \\
Mão de obra montagem do painel na & $3.825,00$ \\
oficina & $2.948,16$ \\
Mão de obra aplicada em campo & $26.772,03$ \\
\hline Total investimento
\end{tabular}

Fonte: Resultados originais da pesquisa

\section{Depreciação do equipamento}

A vida útil do banco de capacitores varia de acordo com a manutenção anual e regime de operação. Estimase que a vida útil seja de cinco anos.

A depreciação foi calculada pelo método linear, em que o seu valor anual é sempre o mesmo, do início ao fim da vida útil. Esse valor foi calculado pela eq. (5) (Frizzone e Andrade Júnior, 2005).

$$
\mathrm{D}=\frac{(\mathrm{C}-\mathrm{R})}{\mathrm{n}}
$$

onde, D: quota anual de depreciação, em R\$; C: valor inicial do bem, em R\$; R: valor residual, em R\$; n: vida útil esperada, em anos.

Desta forma, considerou-se como valor inicial os custos com o equipamento e a manutenção em $10 \%$ do valor no ano, ou seja, 4,88\% ao semestre [a.s.], e o valor residual de $10 \%$ do valor inicial. A depreciação foi calculada com base no valor inicial do equipamento, no caso, R\$19.998,87, não entrando no cálculo os valores previstos no orçamento com a mão de obra de montagem do painel na oficina e mão de obra aplicada em campo, que totalizaram $\mathrm{R} \$ 6.773,16$. A taxa de manutenção de 4,88\% a.s. sobre o valor do equipamento foi aplicada de forma que no primeiro semestre considerou-se como valor do equipamento o previsto para o décimo semestre. Para a manutenção no segundo semestre, considerou como valor do equipamento o previsto para o nono semestre e, assim sucessivamente. Dessa forma, os valores de manutenção aumentaram no decorrer da vida útil do equipamento.

\section{Análise da série histórica do reajuste tarifário}

O reajuste tarifário da distribuidora de energia que atende à unidade consumidora avaliada é composto pela parcela "A" e parcela "B". Na parcela "A", foram inseridos os custos considerados não gerenciáveis, ou seja, controlados pela Agência Reguladora, como por exemplo as quantidades e os valores apurados. Dentro desta parcela estava a compra de energia elétrica para revenda, os encargos setoriais (Taxa de Fiscalização dos Serviços de Energia Elétrica [TFSEE], Pesquisa e Desenvolvimento [P\&D], Conta de Desenvolvimento 
Energético [CDE], Programa de Incentivo às Fontes Alternativas de Energia Elétrica [PROINFA] e Encargos de Serviços do Sistema [ESS]) e os encargos de transmissão (rede básica, contratos de Itaipu, Conexão e Operador Nacional do Sistema [ONS]). A parcela "B" foram custos considerados como gerenciáveis, ou seja, administrados pela concessionária. Entre eles estavam o custo operacional, a remuneração de ativos e a remuneração dos investimentos realizados. O fator " $\mathrm{X}$ " compõe a parcela "B" e teve sua aplicação pelo regulador, ocorrendo sob o pressuposto de que a concessionária tem o dever de aumentar sua eficiência, de forma que os consumidores não venham a pagar preços de monopólio.

O reajuste tarifário anual previsto no contrato de concessão foi calculado para assegurar o repasse integral nas datas de reajuste das variações anuais dos custos observados na parcela "A". No caso da parcela "B", na data do reajuste anual foi reajustada pelo IGPM, considerando a atualização monetária. Entretanto, o referido índice de preço foi corrigido por um fator denominado " $X$ ", determinado pela ANEEL em revisão periódica (ANEEL, 2002). Desta forma, torna-se inviável qualquer pressuposto quanto à variação real dos índices de reajustes para os anos estudados. Portanto, o valor foi estimado com base na média da série histórica dos reajustes tarifários da CEB dos anos de 2004 a 2015. Desta forma, foi inferido um reajuste tarifário de 5,57\% ao ano [a.a.] para as datas ainda não contempladas. Os dados futuros foram estimados sobre a média de cada mês da série histórica de contas anteriores, com o devido reajuste anual.

\section{Análise econômico-financeira do projeto}

O funcionamento do banco de capacitores na unidade armazenadora foi simulado entre setembro de 2016 e setembro de 2021. Neste período, supõe-se que a unidade não pagaria pelo consumo do excedente reativo.

É considerado um financiamento de fomento do BNDES, via Programa para Construção e Ampliação de Armazéns [PCA]. O financiamento considerou o pagamento semestral em 10 parcelas, com juros de $4,16 \%$ a.s.

Para o cálculo do valor do financiamento foi utilizado o método Hamburguês no qual a prestação é variável e o juro incide sobre saldo a pagar (Lima, 2011) ${ }^{6}$. Tanto para o cálculo dos juros quanto para o IOF, utilizou-se a eq. (6).

$$
J=i \times \sum_{j=1}^{k} S D_{j} \times n_{j}
$$

onde i: é a taxa de juros proporcional ao período, em \%; $\mathrm{SD}$ : saldo devedor, em R\$; n: número de períodos que o saldo permanece inalterado.

O sistema de amortização constante [SAC] ou capital foi utilizado como critério de cálculo e indica o abatimento do capital emprestado, mediante parcelas periódicas, calculada pela eq. (7).

$$
\mathrm{A}=\frac{\mathrm{PV}}{\mathrm{n}}
$$

onde A: amortização, em R\$; PV: saldo devedor, em R\$; $\mathrm{n}$ : números de parcelas.

A prestação foi composta pela amortização mais os juros da operação, pelo período de tempo determinado no financiamento, calculada pela eq. (8).

$$
\mathrm{PMT}=\mathrm{J}+\mathrm{A}
$$

A Taxa Mínima de Atratividade [TMA] foi indicada pelo empenho do valor do equipamento em um investimento de baixo risco de títulos públicos, com taxas prefixadas, denominado Tesouro Prefixado com Juros Semestrais [NTNF]. A NTNF no momento da compra foi de 11,46\% a.a., incidindo os tributos do Imposto de Renda [IR], taxas administrativas e de custódia da corretora, a qual foi fixada em $0,5 \%$ a.a.. A tabela 3 apresenta os resultados da simulação pelo Tesouro Direto, demonstrando a remuneração do título no período considerado no Tesouro Prefixado com Juros Semestrais [NTN-F]. A simulação pelo Tesouro Direto gerou ao final do período considerado uma rentabilidade líquida de $4,46 \%$ a.s. após a retirada das taxas e IR. Assim, a TMA adotada foi de 9,11\% a.a., ou seja, 4,46\% a.s. (Tesouro Nacional, 2016).

Após o levantamento dos valores futuros das contas de energia elétrica para o período estudado, com base na progressão anual de 5,57\% como taxa de reajuste, calculou-se o fluxo de caixa mensal, simplificado em semestral. O cálculo das despesas foi baseado no somatório dos juros do financiamento, depreciação e manutenção semestral do equipamento. As receitas foram compostas pelo somatório do consumo reativo e pelo valor residual do equipamento no último semestre. O consumo reativo foi considerado como componente positiva do fluxo de caixa, uma vez que deixará de ser uma despesa excedente em razão dos valores de multas que seriam pagas a concessionária de energia pelo excesso de energia reativa utilizada.

\footnotetext{
${ }^{6}$ Lima, S.M. 2011. Matemática Financeira: uma abordagem prática. Monografia - Programa de Pós-graduação em Matemática do Departamento de Matemática. Instituto de Ciências Exatas - ICEX, Universidade Federal de Minas Gerais, Belo Horizonte, Minas Gerais, Brasil. Disponível em:<http://www.mat.ufmg.br/

espec/monografiasPdf/Monografia_StefaniaMoura.pdf.>. Acesso em: 07 out. 2016.
} 
Tabela 3. Simulação pelo Tesouro Direto: remuneração do título no período no Tesouro Prefixado com Juros Semestrais (NTN-F) para aquisição de um banco de capacitores em uma unidade armazenadora de grãos

\begin{tabular}{lc}
\hline Dias corridos entre as datas de compra e & 1825 \\
vencimento & 1825 \\
Dias corridos entre as datas de compra e venda & 1252 \\
Dias úteis entre as datas de compra e & 1252 \\
vencimento & $26.772,03$ \\
Dias úteis entre as datas de compra e venda & 11,35 \\
Valor investido líquido (R\$) & 0,00 \\
Rentabilidade bruta (\% a.a.*) & 133,86 \\
Taxa de Negociação (0,0\%) & $26.905,89$ \\
Taxa de administração na entrada (R\$) & $41.897,09$ \\
Valor investido bruto (R\$) & 432,32 \\
Valor bruto dos cupons e do resgate (R\$) & \\
Valor da taxa de custódia dos cupons e do & 579,09 \\
resgate (R\$) & 16,13 \\
Valor da taxa de administração dos cupons e do & $2.439,97$ \\
resgate (R\$) & $38.445,72$ \\
Alíquota média de imposto de renda (\%) & 9,11 \\
Imposto de renda (R $\$$ ) & \\
Somatório dos valores líquidos dos cupons e do & \\
resgate (R\$) & \\
Rentabilidade líquida após taxas e I.R. (\% a.a. $*$ ) & \\
*ao ano & \\
Fonte: Simulação pelo site do Tesouro Nacional (2016)
\end{tabular}

Segundo Matos $(2002)^{7}$ é preciso estimar e analisar os indicadores de viabilidade para decisão sobre a viabilidade econômica de um investimento. Dentre os indicadores financeiros mais utilizados, destacam-se o Valor Presente Líquido [VPL], a Taxa Interna de Retorno [TIR] e o período de Payback.

$\mathrm{O}$ valor presente líquido [VPL] tem como função deflacionar para os valores do tempo zero. É definido como a concentração de todos os valores do fluxo de caixa estimados de uma aplicação, calculados a partir da taxa de atratividade e de seu período de duração. A citada taxa em questão representa a taxa de juros mínima que um investidor se propõe a ganhar em um investimento, denominada taxa mínima de atratividade [TMA] (Sviech e Mantovan, 2013). Se o valor do VPL for negativo, o retorno do investimento será menor que o recurso inicialmente aplicado. Dessa forma, sugere-se que o investimento seja recusado. Em contrapartida, se o valor de VPL for positivo, o retorno obtido com o investimento paga o recurso inicialmente aplicado, tornando o projeto viável. A TMA adotada foi o custo de oportunidade, no valor de 9,11\% a.a., ou seja, 4,46\% a.s. de retorno financeiro do Tesouro Direto em relação ao financiamento da quantia total do equipamento. $\mathrm{O}$ VPL foi calculado pela eq. (9).

$$
\mathrm{VPL}=\sum_{\mathrm{t}=0}^{\mathrm{n}} \frac{\mathrm{FC}_{\mathrm{t}}}{(1+\mathrm{TMA})^{\mathrm{t}}}
$$

onde, VPL: valor presente líquido, em R\$; t: período, em semestres; n: vida útil do projeto, em semestres; TMA: taxa mínima de atratividade, em percentagem; FC: fluxo de caixa líquido, em $\mathrm{R} \$$.

A rentabilidade do investimento foi dada pela TIR. Assim como o VPL, ela é usada como critério para a decisão de se aceitar ou rejeitar um investimento. Em geral, o projeto é aceito se a TIR for superior a TMA. Caso contrário, ele é rejeitado. Para a situação de igualdade (TIR=TMA), o investimento encontra-se em uma situação de indiferença (Sviech e Mantovan, 2013). A TIR é estimada igualando a equação do VPL à zero, eq. (10).

$$
\mathrm{TIR}=\sum_{\mathrm{t}=0}^{\mathrm{n}} \frac{\mathrm{FC}_{\mathrm{t}}}{(1+\mathrm{TMA})^{\mathrm{t}}}=0
$$

onde t: período (semestral); n: vida útil do projeto; $\mathrm{FC}_{\mathrm{t}}$ : fluxo de caixa líquido; TMA: taxa mínima de atratividade.

Payback é o período em que o investimento inicial é recuperado e é um indicador de avaliação econômica fácil e direto (Lapponi, 2000). Foi utilizado o Payback simples que foi calculado pelo somatório dos valores dos fluxos de caixa, semestre a semestre, até que o somatório se iguale ao valor inicial aplicado no projeto.

\section{Resultados e discussão}

A depreciação semestral do equipamento foi de $\mathrm{R} \$ 1.799,90$ ou $\mathrm{R} \$ 3.599,80$ por ano. Ao término da vida útil de 5 anos, o valor residual estimado é de R $\$ 1.999,89$ $(10 \%$ do valor inicial). O custo estimado com a manutenção, no primeiro semestre, foi de R\$97,59 e no décimo semestre, de $\mathrm{R} \$ 888,11$, totalizando $\mathrm{R} \$ 4.928,52$ durante a vida útil do equipamento (Figura 2, Tabela 4).

7 Matos, C.M. 2002. Viabilidade e análise de risco de projetos de irrigação: estudo de caso do Projeto Jequitaí (MG). Dissertação de Mestrado em Economia Aplicada Universidade Federal de Viçosa, Viçosa, Minas Gerais, Brasil. Disponível em < http://www.locus.ufv.br/handle/123456789/768>. Acesso em: 05 set. 2016. 


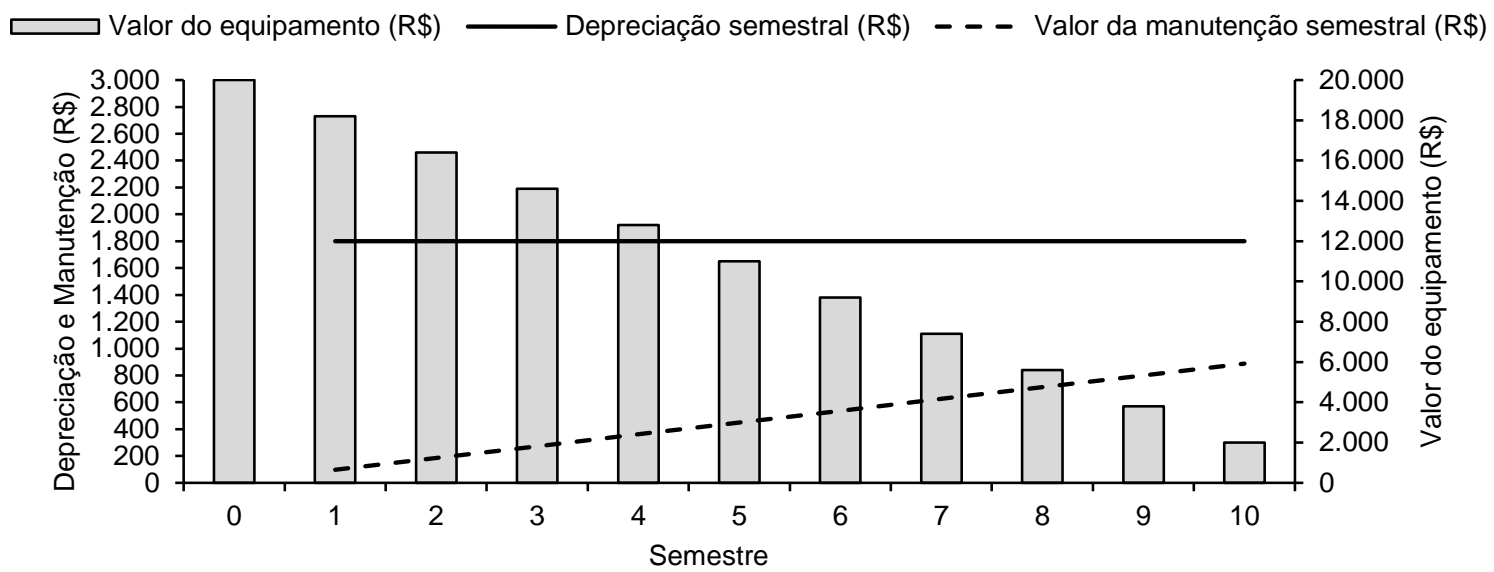

Figura 2. Valor atualizado do equipamento, da depreciação e da manutenção do banco de capacitores no semestre Fonte: Resultados originais da pesquisa

Tabela 4. Estimativas da Depreciação, do Valor Residual e da manutenção (\% e valor) no semestre

\begin{tabular}{ccccc}
\hline Semestre & Depreciação & Valor Residual & Manutenção & Manutenção \\
\hline & - & - & $19.998,87$ & - \\
1 & $1.799,90$ & $18.198,97$ & 4,88 & - \\
2 & $1.799,90$ & $16.399,07$ & 4,89 & 185,43 \\
3 & $1.799,90$ & $14.599,18$ & 4,88 & 273,26 \\
4 & $1.799,90$ & $12.799,28$ & 4,88 & 361,10 \\
5 & $1.799,90$ & $10.999,38$ & 4,88 & 448,93 \\
6 & $1.799,90$ & $9.199,48$ & 4,88 & 536,77 \\
7 & $1.799,90$ & $7.399,58$ & 4,88 & 624,60 \\
8 & $1.799,90$ & $5.599,68$ & 4,88 & 712,44 \\
9 & $1.799,90$ & $3.799,79$ & 4,88 & 800,27 \\
\hline
\end{tabular}

Fonte: Resultados originais da pesquisa

Os valores das faturas de energia elétrica com base no reajuste tarifário de 5,57\% para o período de execução do projeto são apresentados na tabela 5 . Os valores da EREX fora de ponta variaram de $\mathrm{R} \$ 988,73$ a $\mathrm{R} \$$ 1402,10. Comparando-se esses valores com os valores projetados para EREX ponta e DREX, verificou-se que os dois últimos foram praticamente insignificantes, evidenciando que as multas aplicadas a unidade armazenadora provenientes do consumo reativo são oriundas da EREX fora de ponta. Os reduzidos valores da projeção de EREX ponta estão relacionados ao horário de funcionamento da unidade armazenadora, a qual opera no horário comercial das $8 \mathrm{~h} 00$ às $17 \mathrm{~h} 00$. Considerando as projeções de valores de consumo reativo para os cinco anos de vida útil do equipamento e a correção do fator de potência pela instalação do banco de capacitores, a unidade armazenadora deixou de gastar com consumo reativo a quantia de $\mathrm{R} \$ 70.580,91$.

Fragoas $(2008)^{8}$ realizou um estudo com o dimensionamento de bancos de capacitores em uma cidade com cerca de 150.000,00 habitantes. O valor do investimento inicial para a aquisição de 9 bancos capacitores de $600 \mathrm{kVAr}$ e cinco bancos de $1200 \mathrm{kVAr}$ foi de $\mathrm{R} \$ 61.910,68$. Ao final de cinco anos, a receita gerada pela redução da perda técnica nos sistemas de alta tensão foi de $\mathrm{R} \$ 274.232,32$. Apesar de apresentarem dimensões de projetos distintas, estes resultados vêm de encontro com os verificados no presente estudo, evidenciando a economia obtida nas faturas de energia elétrica por meio da instalação de banco de capacitores.

${ }^{8}$ Fragoas, A.G. 2008. Estudo de caso do uso de bancos de capacitores em uma rede de distribuição primária - indicativos da sua viabilidade econômica. Trabalho de conclusão de Curso de Engenharia Elétrica. Universidade de São Paulo, São Carlos, São Paulo, Brasil. Disponível em:

<http://www.tcc.sc.usp.br/tce/disponiveis/18/180500/tce-26032010-145421/?\&lang=br>. Acesso em: 05 mar. 2016. 
Tabela 5. Simulação dos valores das faturas mensais de elétrica com reajuste anual previsto de 5,57\% ao ano, em R $\$$, de outubro de 2016 a setembro de 2021

(continua)

\begin{tabular}{|c|c|c|c|c|c|}
\hline Mês/Ano & EREX f.ponta ${ }^{1}$ & EREX ponta ${ }^{2}$ & DREX $^{3}$ & $\begin{array}{c}\text { Fatura sem o } \\
\text { consumo reativo }\end{array}$ & $\begin{array}{c}\text { Fatura com o } \\
\text { consumo reativo }\end{array}$ \\
\hline & \multicolumn{5}{|c|}{ 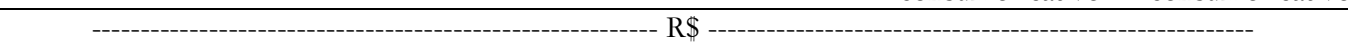 } \\
\hline out-16 & $1.229,26$ & 0,24 & 0,00 & $4.855,16$ & $6.084,66$ \\
\hline nov-16 & $1.112,06$ & 1,95 & 0,00 & $5.261,23$ & $6.375,25$ \\
\hline dez-16 & $1.126,56$ & 0,00 & 0,00 & $5.107,62$ & $6.234,19$ \\
\hline jan-17 & $1.219,41$ & 0,63 & 0,00 & $3.804,24$ & $5.024,29$ \\
\hline fev-17 & $1.204,28$ & 0,00 & 0,00 & $4.056,84$ & $5.261,12$ \\
\hline mar-17 & $1.137,96$ & 0,11 & 0,00 & $3.862,22$ & $5.000,29$ \\
\hline abr-17 & $1.115,34$ & 0,00 & 0,00 & $4.660,23$ & $5.775,57$ \\
\hline maio-17 & $1.112,70$ & 0,46 & 20,58 & $3.973,13$ & $5.106,87$ \\
\hline jun-17 & 988,73 & 0,00 & 0,00 & $6.707,22$ & $7.695,95$ \\
\hline jul-17 & $1.095,82$ & 0,00 & 0,00 & $5.373,54$ & $6.469,36$ \\
\hline ago-17 & $1.061,23$ & 0,00 & 0,00 & $3.201,30$ & $4.262,53$ \\
\hline set-17 & $1.344,33$ & 0,00 & 0,00 & $3.238,49$ & $4.582,82$ \\
\hline out-17 & $1.252,09$ & 0,24 & 0,00 & $4.945,31$ & $6.197,64$ \\
\hline nov-17 & $1.132,71$ & 1,99 & 0,00 & $5.358,91$ & $6.493,61$ \\
\hline dez-17 & $1.147,48$ & 0,00 & 0,00 & $5.202,46$ & $6.349,94$ \\
\hline jan-18 & $1.236,39$ & 0,64 & 0,00 & $3.857,22$ & $5.094,25$ \\
\hline fev-18 & $1.221,05$ & 0,00 & 0,00 & $4.113,33$ & $5.334,38$ \\
\hline mar-18 & $1.153,81$ & 0,11 & 0,00 & $3.916,00$ & $5.069,92$ \\
\hline abr-18 & $1.130,87$ & 0,00 & 0,00 & $4.725,12$ & $5.855,99$ \\
\hline maio-18 & $1.128,20$ & 0,46 & 20,87 & $4.028,46$ & $5.177,99$ \\
\hline jun-18 & $1.002,49$ & 0,00 & 0,00 & $6.800,62$ & $7.803,12$ \\
\hline jul-18 & $1.111,08$ & 0,00 & 0,00 & $5.448,37$ & $6.559,45$ \\
\hline ago-18 & $1.076,01$ & 0,00 & 0,00 & $3.245,88$ & $4.321,89$ \\
\hline set-18 & $1.363,05$ & 0,00 & 0,00 & $3.283,58$ & $4.646,63$ \\
\hline out-18 & $1.269,52$ & 0,25 & 0,00 & $5.014,17$ & $6.283,94$ \\
\hline nov-18 & $1.148,48$ & 2,02 & 0,00 & $5.433,54$ & $6.584,04$ \\
\hline dez-18 & $1.163,46$ & 0,00 & 0,00 & $5.274,90$ & $6.438,36$ \\
\hline jan-19 & $1.250,17$ & 0,65 & 0,00 & $3.900,19$ & $5.151,00$ \\
\hline fev-19 & $1.234,65$ & 0,00 & 0,00 & $4.159,15$ & $5.393,80$ \\
\hline mar-19 & $1.166,66$ & 0,11 & 0,00 & $3.959,63$ & $5.126,40$ \\
\hline abr-19 & $1.143,47$ & 0,00 & 0,00 & $4.777,76$ & $5.921,23$ \\
\hline maio-19 & $1.140,77$ & 0,47 & 21,10 & $4.073,34$ & $5.235,67$ \\
\hline jun-19 & $1.013,66$ & 0,00 & 0,00 & $6.876,38$ & $7.890,04$ \\
\hline jul-19 & $1.123,45$ & 0,00 & 0,00 & $5.509,07$ & $6.632,52$ \\
\hline ago-19 & $1.087,99$ & 0,00 & 0,00 & $3.282,04$ & $4.370,03$ \\
\hline set-19 & $1.378,23$ & 0,00 & 0,00 & $3.320,16$ & $4.698,40$ \\
\hline out-19 & $1.283,66$ & 0,25 & 0,00 & $5.070,03$ & $6.353,94$ \\
\hline nov-19 & $1.161,28$ & 2,04 & 0,00 & $5.494,06$ & $6.657,38$ \\
\hline dez-19 & $1.176,42$ & 0,00 & 0,00 & $5.333,66$ & $6.510,08$ \\
\hline jan-20 & $1.261,77$ & 0,65 & 0,00 & $3.936,39$ & $5.198,82$ \\
\hline fev-20 & $1.246,11$ & 0,00 & 0,00 & $4.197,77$ & $5.443,87$ \\
\hline mar-20 & $1.177,49$ & 0,11 & 0,00 & $3.996,39$ & $5.173,99$ \\
\hline abr-20 & $1.154,08$ & 0,00 & 0,00 & $4.822,11$ & $5.976,20$ \\
\hline maio-20 & $1.151,36$ & 0,47 & 21,29 & $4.111,15$ & $5.284,28$ \\
\hline jun-20 & $1.023,07$ & 0,00 & 0,00 & $6.940,22$ & $7.963,29$ \\
\hline jul-20 & $1.133,88$ & 0,00 & 0,00 & $5.560,21$ & $6.694,09$ \\
\hline ago-20 & $1.098,09$ & 0,00 & 0,00 & $3.312,51$ & $4.410,60$ \\
\hline set-20 & $1.391,03$ & 0,00 & 0,00 & $3.350,99$ & $4.742,02$ \\
\hline out-20 & $1.295,58$ & 0,25 & 0,00 & $5.117,10$ & $6.412,93$ \\
\hline nov-20 & $1.172,06$ & 2,06 & 0,00 & $5.545,07$ & $6.719,19$ \\
\hline dez-20 & $1.187,34$ & 0,00 & 0,00 & $5.383,18$ & $6.570,52$ \\
\hline jan-21 & $1.271,81$ & 0,66 & 0,00 & $3.967,72$ & $5.240,19$ \\
\hline fev-21 & $1.256,02$ & 0,00 & 0,00 & $4.231,17$ & $5.487,19$ \\
\hline mar-21 & $1.186,86$ & 0,11 & 0,00 & $4.028,19$ & $5.215,16$ \\
\hline
\end{tabular}


Tabela 5. Simulação dos valores das faturas mensais de elétrica com reajuste anual previsto de 5,57\% ao ano, em R\$, de outubro de 2016 a setembro de 2021

(conclusão)

\begin{tabular}{|c|c|c|c|c|c|}
\hline Mês/Ano & EREX f.ponta ${ }^{1}$ & EREX ponta ${ }^{2}$ & DREX $^{3}$ & $\begin{array}{c}\text { Fatura sem o } \\
\text { consumo reativo }\end{array}$ & $\begin{array}{c}\text { Fatura com o } \\
\text { consumo reativo }\end{array}$ \\
\hline & \multicolumn{5}{|c|}{----------------------------------------------------------------R\$---------------------------------------------------------- } \\
\hline abr-21 & 1163,27 & 0,00 & 0,00 & $4.860,48$ & $6.023,75$ \\
\hline maio-21 & $1.160,52$ & 0,48 & 21,46 & $4.143,86$ & $5.326,32$ \\
\hline jun-21 & $1.031,21$ & 0,00 & 0,00 & $6.995,44$ & $8.026,65$ \\
\hline jul-21 & $1.142,91$ & 0,00 & 0,00 & $5.604,45$ & $6.747,36$ \\
\hline ago-21 & $1.106,83$ & 0,00 & 0,00 & $3.338,87$ & $4.445,70$ \\
\hline set-21 & $1.402,10$ & 0,00 & 0,00 & $3.377,65$ & $4.779,75$ \\
\hline Total & $70.458,2$ & 17,40 & 105,30 & $277.325,51$ & $347.906,42$ \\
\hline
\end{tabular}

${ }^{1}$ Energia reativa excedente fora de ponta (EREX f.ponta), ${ }^{2}$ Energia reativa excedente na ponta (EREX ponta), ${ }^{3}$ Demanda Reativa Excedente [DREX]

Fonte: Resultados originais da pesquisa

A figura 3 apresenta a estimativa dos valores das faturas mensais de energia elétrica, com e sem o consumo reativo, no período da vida útil do banco de capacitores (5 anos). A média de valores da energia reativa fora de ponta foi de $\mathrm{R} \$ 1.174,30$. Os valores máximos e mínimos do consumo reativo foram obtidos em setembro de 2021 e junho de 2017, de $\mathrm{R} \$ 1.402,10$ e $\mathrm{R} \$$ 998,73, respectivamente. As variações são decorrentes do maior (ou menor) consumo de energia elétrica em função das quantidades de produtos que entram ou saem no mês, que afeta o número de horas de funcionamento de motores elétricos no transporte dos grãos (elevadores de cargas e correias transportadoras) assim como do sistema de aeração e secagem.

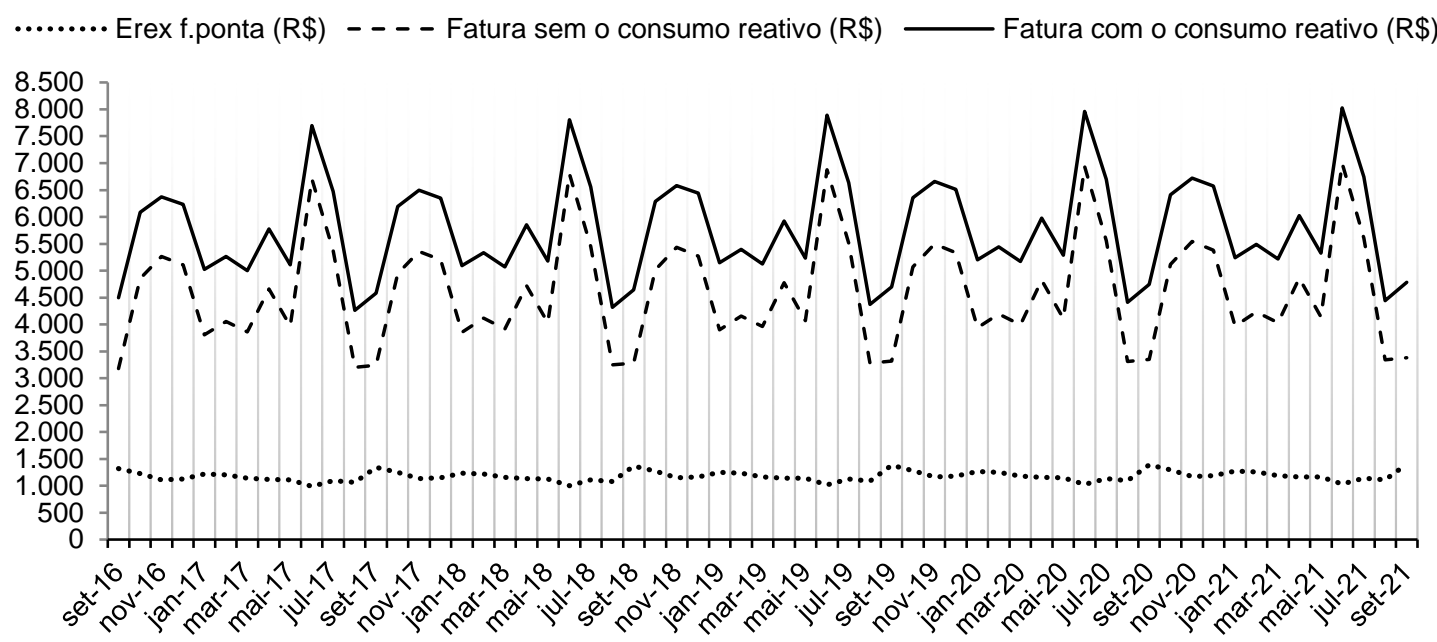

Figura 3. Estimativa dos valores das faturas mensais de energia elétrica, com e sem o consumo de reativo, e valores de energia reativa fora de ponta entre setembro de 2016 e setembro de 2021

Fonte: Resultados originais da pesquisa

$\mathrm{Na}$ simulação do financiamento, os juros foram calculados sobre o saldo devedor. No primeiro semestre, o seu valor foi de $\mathrm{R} \$ 1.189,30$ e de $\mathrm{R} \$ 111,77$ no décimo semestre, totalizando $\mathrm{R} \$ 6.197,56$ ao final do período. Sobre o saldo devedor foi abatido semestralmente o valor dos juros somado ao capital, que totalizou no final do período de reposição do financiamento o valor de $\mathrm{R} \$ 32.969,59$ (Tabela 6).
O fluxo de caixa é apresentado semestralmente de forma resumida na tabela 7. Nas despesas foram incluídos os gastos com juros do financiamento, depreciação e manutenção do banco capacitor. Os valores sofrem pouca variação ao longo do tempo. Nas receitas estão os valores referentes ao consumo reativo de energia somado ao valor residual do equipamento, incluído no último semestre. Dessa forma, a receita total foi de $\mathrm{R} \$ 72,580.80$. 
Tabela 6. Simulação de financiamento de um banco de capacitores para uma unidade armazenadora de grãos pela linha de crédito do Programa para Construção e Ampliação de Armazéns [PCA] do Banco Nacional do Desenvolvimento [BNDES], Banco do Brasil

\begin{tabular}{|c|c|c|c|c|c|}
\hline Parcela & Data da Parcela & Juros & Capital & Prestação & Saldo Devedor \\
\hline & & \multicolumn{4}{|c|}{ - } \\
\hline 0 & 09.2016 & 0,00 & 0,00 & $101,73^{*}$ & $26.772,03$ \\
\hline 1 & 03.2017 & $1.189,30$ & $2.677,20$ & $3.866,50$ & $24.094,83$ \\
\hline 2 & 09.2017 & $1.000,34$ & $2.677,20$ & $3.677,54$ & $21.417,63$ \\
\hline 3 & 03.2018 & 889,19 & $2.677,20$ & $3.566,39$ & $18.740,43$ \\
\hline 4 & 09.2018 & 778,05 & $2.677,20$ & $3.455,25$ & $16.063,23$ \\
\hline 5 & 03.2019 & 666,90 & $2.677,20$ & $3.344,10$ & $13.386,03$ \\
\hline 6 & 09.2019 & 558,86 & $2.677,20$ & $3.236,06$ & $10.708,83$ \\
\hline 7 & 03.2020 & 447,09 & $2.677,20$ & $3.124,29$ & $8.031,63$ \\
\hline 8 & 09.2020 & 334,38 & $2.677,20$ & $3.011,58$ & $5.354,43$ \\
\hline 9 & 03.2021 & 221,68 & $2.677,20$ & $2.898,88$ & $2.677,23$ \\
\hline 10 & 09.2021 & 111,77 & $2.677,23$ & $2.789,00$ & 0,00 \\
\hline Total & & $6.197,56$ & $26.772,03$ & $32.969,59$ & \\
\hline
\end{tabular}

*Cálculo do IOF $(0,38 \%)$ sobre o valor total financiado ( $\mathrm{R} \$ 26.772,03)$

Fonte: Resultados originais da pesquisa

Tabela 7. Fluxo de caixa semestral da implantação do banco de capacitores em uma unidade armazenadora de grãos em Brasília, Distrito Federal, compilado dos meses de outubro de 2016 a setembro de 2021

\begin{tabular}{|c|c|c|c|c|}
\hline Semestre & 0 & 1 & 2 & 3 \\
\hline & $\cdots$ & & & \\
\hline Despesa & - & $3.086,79$ & $2.985,67$ & $2.962,35$ \\
\hline Receita & - & $7.032,47$ & $6.739,18$ & $7.146,51$ \\
\hline Fluxo de caixa comum & $-26.772,03$ & $3.945,68$ & $3.753,51$ & $4.184,15$ \\
\hline Fluxo de caixa acumulado & $-26.772,03$ & $-22.826,35$ & $-19.072,83$ & $-14.888,68$ \\
\hline \multirow[t]{2}{*}{ Semestre } & 4 & 5 & 6 & 7 \\
\hline & ---------------- & --------------- & ---------- & ------------- \\
\hline Despesa & $2.939,05$ & $2.915,73$ & $2.895,53$ & $2.871,59$ \\
\hline Receita & $6.833,03$ & $7.235,96$ & $6.909,15$ & $7.309,79$ \\
\hline Fluxo de caixa comum & $3.893,98$ & 4.320 .23 & $4.013,62$ & $4.438,20$ \\
\hline Fluxo de caixa acumulado & $-10.994,70$ & $-6.674,47$ & $-2.660,85$ & $1.777,34$ \\
\hline \multirow[t]{2}{*}{ Semestre } & 8 & 9 & 10 & \\
\hline & & ----------- & -------------- & 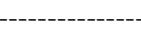 \\
\hline Despesa & $2.846,72$ & $2.821,85$ & $2.799,78$ & \\
\hline Receita & $6.973,29$ & $7.372,76$ & $9.028,66$ & \\
\hline Fluxo de caixa comum & $4.126,57$ & $4.550,91$ & $6.228,88$ & \\
\hline Fluxo de caixa acumulado & $5.903,91$ & $10.454,82$ & $16.683,70$ & \\
\hline
\end{tabular}

Fonte: Resultados originais da pesquisa

Os resultados da análise econômica - VPL, TIR e Payback - estão na tabela 8. Com TMA de 4,46\% a.s, o VPL foi de R\$7.228,63, indicando que o projeto foi capaz de quitar o investimento inicial, bem como garantir o retorno financeiro mínimo estabelecido pelo investidor.

Tabela 8. Valor Presente Líquido [VPL], Taxa Interna de Retorno [TIR] e Payback da implantação do banco de capacitores em uma unidade armazenadora de grãos em Brasília, Distrito Federal, com projeção de cinco anos

\begin{tabular}{|l|l|}
\hline Indicadores econômicos & Resultados \\
\hline VPL & $\mathrm{R} \$ 7.228,63$ \\
\hline TIR & $9,34 \%$ ao semestre \\
\hline Payback & Três anos e quatro meses \\
\hline
\end{tabular}

Fonte: Resultados originais da pesquisa
A TIR estimada foi de 9,34\% a.s, que é superior à TMA, o que indica a rentabilidade do investimento. $O$ Payback é encontrando quando o fluxo de caixa acumulado se torna maior do que o investimento inicial. Para o investimento analisado neste estudo, o Payback foi de três anos e quatro meses.

\section{Conclusão}

Considerando-se os resultados dos indicadores financeiros Valor Presente Líquido, Taxa Interna de Retorno e Payback, verificou-se que a instalação do banco de capacitores na unidade armazenadora de grãos é um investimento viável e atrativo financeiramente. No presente estudo, considerou-se o valor médio de $45 \%$ de utilização da capacidade estática do armazém. Portanto, havia a possibilidade de aumentar o nível de ocupação do armazém, resultando em maiores receitas e retorno do 
investimento em menor período de tempo. Além dos benefícios econômicos, o banco de capacitores pode otimizar o consumo de energia elétrica e auxiliar a diminuir quedas de tensão do sistema elétrico, reduzindo perdas.

\section{Referências}

Agência Nacional de Energia Elétrica [ANEEL]. 2002. Sobre a Agência Nacional de Energia Elétrica - Nota

Técnica n. 326. Cálculo do fator X na revisão tarifária periódica das concessionárias de distribuição de energia elétrica. Disponivel em:

<http://www2.aneel.gov.br/aplicacoes/Audiencia_P ublica/audiencia_proton/2002/ap023/NT_FX_29ou t02.pdf>. Acesso em: 5 set. 2016.

Agência Nacional de Energia Elétrica [ANEEL]. 2012. Resolução Normativa no 479, de 3 de abril de 2012. Altera a Resolução Normativa no 414 , de 9 de setembro de 2010, que estabelece as Condições Gerais de Fornecimento de Energia Elétrica de forma atualizada e consolidada. Disponível em:

<http://www2.aneel.gov.br/aplicacoes/audiencia/ar quivo/2011/049/resultado/ren2012479.pdf>. Acesso em: 08 mar. 2016.

Comitê de Distribuição de Energia Elétrica [CODI]. 1993. Manual de Conversação de Energia Elétrica na Indústria (Alta Tensão). ELETROBRÁS, PROCEL, Rio de Janeiro, Rio de Janeiro, Brasil.

Comitê de Distribuição de Energia Elétrica [CODI]. 2004. Energia reativa Excedente, Manual de orientação aos consumidores. Disponível em: <http://www.edp.com.br/distribuicao/edpbandeirante/informacoes/grandesclientes/normas-emanuais/Documents/Manual $\% 20 d e \% 20$ Orienta $\%$ C3 $\%$ A $7 \%$ C $3 \%$ A30 $\% 20 \% 20$

Energia\%20Reativa\%20Excedente.pdf $>$. Acesso em: 08 mar. 2016.

Companhia Energética de Brasília [CEB]. 2016. CEB Distribuição. Disponível em:

<http://www.ceb.com.br/>. Acesso em: 07 out. 2016.

Duailibe, P. 2000. Capacitores: Instalação e correção do fator de potência. Centro Federal de Educação Tecnológica Celso Suckow da Fonseca. 36 p. Rio de Janeiro, Rio de Janeiro. Brasil. Disponível em: <http://www.uff.br/lev/downloads/apostilas/Capac itores.pdf $>$. Acesso em: 05 mar. 2016.

Flarys, F. 2006. Eletrotécnica Geral. Editora Manole, São Paulo, São Paulo. Brasil.

Frizzone, J.A.; Andrade Júnior, A.S. 2005. Planejamento de irrigação: Análise de decisão e investimentos. Embrapa Informação Tecnológica, Brasília, Distrito Federal, Brasil.

Instituto Nacional de Metrologia, Qualidade e Tecnologia [INMETRO]. 2013. Portaria Inmetro/Dimel no 0219, de 15 de outubro de 2013. Disponível em:
<http://www.inmetro.gov.br/legislacao/pam/pdf/P AM005712.pdf>. Acesso em: 07 mar. 2016.

Lapponi, J.C. 2000. Projetos de investimento: construção e avaliação do fluxo de caixa: modelos em Excel. Laponni Treinamento e Editora. São Paulo, São Paulo, Brasil.

Mamede Filho, J. 2007. Instalações Elétricas Industriais. Editora LTC, $7^{\text {a }}$ Edição. Rio de Janeiro, Rio de Janeiro, Brasil.

Receita Federal Brasileira [RFB]. 1998. Instrução Normativa $\mathrm{N}^{\circ} 162$ de 31 de dezembro de 1998. Fixa prazo de vida útil e taxa de depreciação dos bens que relaciona. Diário Oficial da União, Brasília. 07 jan. 1999. Seção 1, p.5.

Receita Federal Brasileira [RFB]. 2012. Instrução Normativa N¹234 de 11 de janeiro de 2012. Dispõe sobre a retenção de tributos nos pagamentos efetuados pelos órgãos da administração pública federal direta, autarquias e fundações federais, empresas públicas, sociedades de economia mista e demais pessoas jurídicas que menciona a outras pessoas jurídicas pelo fornecimento de bens e serviços. Diário Oficial da União, Brasília. 12 jan. 2012. Seção 1, p.22.

Sviech, V.; Mantovan, E.A. 2013. Análise de investimentos: controvérsias na utilização da TIR e VPL na comparação de projetos. Revista Eletrônica Percurso 13: 1-28. Disponível em: $<$ http://revista.unicuritiba.edu.br/index.php/percurs o/article /view/657/495>. Acesso em: 15 ago. 2016.

Tesouro Nacional. 2016. Indicadores Econômicos. Disponivel em: < http://www.tesouro.gov.br//tesouro-direto-indicadores $>$. Acesso em: 05 set. 2016. 